\title{
Valoración de la calidad de sitios web turísticos: Estudio empírico basado en IEW
}

\section{Evaluation of the quality of tourism websites: empirical study based on IEW}

\author{
Miguel A. Ríos-Martín (RIOS-MARTIN, M. A.) ${ }^{*}$ \\ Pedro R. Palos-Sánchez (PALOS-SANCHEZ, P. R.) ${ }^{* *}$ \\ Mariel Cáceres-Genao (CACERES, M.) ${ }^{* * *}$
}

RESUMEN - El presente análisis se ha centrado en la valoración de la calidad web de los hoteles de 5 estrellas de Madrid; todo ello utilizando como herramienta principal y única al índice de calidad web (IEW), mediante el cual se pudo conocer la idoneidad y la calidad de cada una de las webs analizadas. Siendo las características a las que refiere este análisis: la accesibilidad, la velocidad, la navegabilidad y usabilidad, y la calidad del contenido de las webs. Todas estas categorías, con sus referentes ítems, y en el caso del contenido, con sus respectivos ítems y sub-categorías: contenido informativo, transaccional y contractual. Se han obtenido en el análisis tras aplicar dicho índice, resultados bastantes favorables para cada una de las webs analizadas, siendo más o menos favorables según la web y sus características individuales.

Palabras clave: Turismo; Calidad web; Web sites; Interfaz web; Web 2.0.

ABSTRACT - The present analysis has focused on the assessment of the web quality of 5 star hotels in Madrid; Using as a main and unique tool the web quality index (IEW), through which it was possible to know the suitability and quality of each of the analyzed webs. Being the characteristics to which this analysis refers: the accessibility, the speed, the navigability and usability, and the quality of the content of the webs. All these categories, with their referring items, and in the case of the content, with their respective items and sub-categories: information content, transactional and contractual. We obtained in the analysis after applying this index, quite favorable results for each of the analyzed webs, being more or less favorable according to the web and its individual characteristics.

Key words: Tourism; Web quality; Web sites; Web interface; Web 2.0.

\footnotetext{
* Profesor Colaborador Doctor del Departamento de Economía Financiera y Dirección de Operaciones de la Universidad de Sevilla. Es miembro del Grupo de Investigación DOS (Dirección de Operaciones y Servicios en Turismo). Endereço físico para correspondência: Facultad de Turismo y Finanzas de la Universidad de Sevilla, Av. San Francisco Javier, s/n. 41018-Sevilla, España, e-mail: rios@us.es

** Profesor Asociado Doctor del Departamento de Dirección de Empresa de la Universidad de Extremadura. Es miembro del Grupo de Investigación MARKETUR Research Group de la Universidad de Extremadura. Endereço físico para correspondência: Facultad de Empresa, Finanzas y Turismo de la Universidad de Extremadura, Av. Universidad, s/n. 10003 - Cáceres, España, e-mail: ppalos@unex.es.

Formación: Graduada Universitaria en Turismo. Universidad de Sevilla, Endereço físico para correspondência: Facultad de Turismo y Finanzas de la Universidad de Sevilla, Av. San Francisco Javier, s/n. 41018-Sevilla, España, e-mail: marielcaceresgenao@ hotmail.com
} 


\section{INTRODUCCIÓN}

Con el nacimiento del Internet y posteriormente, de la World Wide Web, la forma en la que las personas interactúan, se relacionan y evolucionan ha cambiado radicalmente. No se puede decir que Internet posea una larga historia comparada con otros fenómenos, sin embargo, a pesar de su corta existencia ha tenido un desarrollo rápido y cuidadoso. Hoy en día se ha convertido en parte fundamental de cada organización y de la sociedad en general, ya que ha pasado a considerarse una herramienta que permite y facilita la comunicación, pero que también abre las puertas hacia un sin número de actividades.

De cara al sector del turismo, Rastrollo y Alarcón (1999), afirman que la aparición de Internet ha tenido gran influencia en todas las etapas del proceso de decisión de compra del consumidor. Además, consideran que se ven afectadas todas las etapas de dicho proceso, desde la consideración del deseo de viajar, a la post-compra del viaje, pasando por la búsqueda de información y evaluación de posibles alternativas, es decir, decisión de compra, acto de compra y finalmente post-compra.

En el campo del Marketing (KOTLER, 1998), se considera que Internet ha introducido cambios en las denominadas "4 p": Product, Price, Place, Promotion, ya que afecta, a la promoción y a la distribución; afirmando que "Internet se ha convertido en el principal medio de información del turista y de emisión de información de los anunciantes: tour-operadores, destinos, hoteles, etc." (DÍAZ-LUQUE; JIMÉNEZ MARÍN, 2013, p. 40).

Parece indiscutible por tanto, que el principal uso que los consumidores hacen de Internet es la búsqueda de información para tomar sus decisiones de compra, debido a la comodidad que les ofrece el tener disponible tanta información como necesiten "dónde, cuándo y en la cantidad que quieran" (PARK; WANG; FESENMAIER, 2011, p. 402), tal y como se había afirmado anteriormente. Otros autores, (MILLS; LAW, 2004; XIANG; FESENMAIER, 2008; BUHALIS; LAW，2008; WERTHNER; KLEIN，1999) han destacado también esta ventaja de Internet en el ámbito del turismo, afirmando que ha reconfigurado la forma de buscar información y planificar los viajes, así como la compra de los productos relacionados con el turismo.

Las tecnologías y el gran impacto de éstas en el sector turístico, han propiciado que la calidad web haya tomado una gran relevancia, puesto que la información que va 
reuniendo el usuario y posible cliente a través de Internet repercute enormemente en la percepción y creación de imagen personal de la marca, la empresa y de sus productos.

Por otra parte, el nacimiento de la Web 2.0 ha supuesto un cambio evidente en todo lo que este fenómeno se refiere. Según O’Reilly (2005, p. 1), la web 2.0 puede definirse de la siguiente manera:

La web 2.0 es la red como plataforma, involucrando a todos los dispositivos conectados. Las aplicaciones Web 2.0 son las que aprovechan mejor las ventajas de esa plataforma, ofreciendo software como servicio de actualización continua que mejora en la medida que la cantidad de usuarios aumenta, consumiendo y mezclando datos de diferentes fuentes, incluyendo usuarios individuales, mientras genera sus propios datos en una forma que permite ser remezclado por otros, creando efectos de red a través de una arquitectura de participación y dejando atrás a la metáfora de la web 1.0, con el fin de ofrecer experiencias más envolventes al usuario.

De esta manera, convergencia, usabilidad y participación son conceptos claves en la filosofía de la Web 2.0. Compartir, comunicar, conversar y cooperar son las $4 \mathrm{Cs}$ de la este tipo de Web, que determina el poder del usuario online para crear, difundir y compartir contenidos (CASTELLÓ MARTÍNEZ, 2011). En la Web 2.0 el usuario empieza a ser un consumidor activo de contenidos, ya que puede generarlos, editarlos y compartirlos con su comunidad. El poder del usuario, que personaliza los contenidos en base a sus gustos, hobbies, modo de vida e intereses y forma parte de una red social, tiene una gran influencia en el marketing viral. Además, la accesibilidad a la información con que cuenta el usuario a través de las herramientas de la Web 2.0 ha modificado los hábitos de los consumidores, los cuales se vuelven más exigentes a la hora de tomar decisiones de compra y consumo (CASTELLÓ MARTÍNEZ, 2010).

Así bien, en el sector del turismo, se podría decir que son numerosas las empresas turísticas que poseen su propia página web para llegar a más personas, y ganar así mayor valoración y posicionamiento en el mercado.

Hoy en día, que las organizaciones cuenten con una página web de calidad, ya no es simplemente una opción, sino una obligación, puesto que con la llegada del smartphone y la constante evolución tecnológica, en la que el mundo se encuentra, las páginas web se han convertido en un recurso que cada vez cobra más importancia, debido a que es normal que la mayoría de las gestiones se realicen por Internet, y obviamente a través de estas. Existen establecimientos turísticos, como por ejemplo el 
Enoturísmo, donde el sitio web es el medio para la captación de clientes que más se emplea (DEL RIO et al., 2014). Otros estudios en sectores turísticos, como el Turismo Gastronómico, en concreto las rutas del queso, emplearon las webs de denominación de origen para estudiar e investigar el sector (FOLGADO-FERNANDEZ et al., 2017).

Debido a todo ello, en los últimos años se han desarrollado numerosos estudios (HEITMANN; LEHMANN; HERRMANN, 2007; WOODSIDE; DION, 2010) encaminados a analizar la idoneidad de los espacios web de los destinos turísticos, para promocionarlos de la forma más adecuada, es decir, dando la información y seguridad suficiente para que el destino pueda ser seleccionado por el consumidor al finalizar su proceso de decisión de compra.

Tras todo lo anteriormente expuesto, se puede finalizar matizando que los avances tecnológicos y el crecimiento del uso de Internet, las redes sociales y sobre todo las páginas web, han dado a conocer la gran importancia de estas herramientas en el sector turístico y en muchísimos otros.

Se toman así, como objeto de este análisis las páginas web de los establecimientos turísticos (hoteles de 5 estrellas ubicados en Madrid), debido a la gran influencia que tienen este tipo de web sobre los clientes, lo cual es algo crucial para rentabilidad de los hoteles; además se parte del hecho de que es altamente comprobable que la mayoría de establecimientos turísticos en el mundo y en España cuenta con su propia página web, ya es cosa del pasado el que esta herramienta fuera solo cosa de las grandes empresas. Además de que por otra parte, también se conocerá indirectamente el grado de efectividad y competitividad de dichas webs frente a otras, ya que es lógico que si se analizan diversas webs encaminadas hacia el mismo objetivo se podrá percibir mejor las carencias y puntos fuertes de las mismas en comparación con otras.

Para conseguir este objetivo, en esta investigación se analizó a través del método IEW, la calidad de las webs de los hoteles que contaban con una categoría de 5 estrellas y estaban ubicados en Madrid.

De esta manera, se pudo observar un índice que mide la estrategia web relacionada con la sede online, es decir, que estudió las acciones que permiten que el usuario sea atraído a la página de la compañía y pueda utilizarla de forma sencilla, entre otros factores claves. Por tanto, el objetivo fue: analizar, verificar y clasificar las características de las páginas web a tratar, para obtener unas valoraciones que 
permitiesen conocer la calidad de cada una de las webs objeto de análisis, para de esta manera dar a conocer sus puntos fuertes, así como sus debilidades.

\section{REVISIÓN DE LA LITERATURA}

Para la realización de este trabajo se consultaron diversos autores y fuentes, los cuales facilitaron la obtención de información valida y veraz a cerca de la calidad web.

Es importante destacar, que la evaluación del rendimiento de los sitios web ha sido una preocupación recurrente de los investigadores en diferentes campos, además, tras la revisión de la literatura se ha podido conocer que la calidad web ha comenzado a tomarse en consideración a partir de que el e-commerce comenzara a ganar más popularidad entre la población, y que por dicha razón las empresas tomaron conciencia de la importancia de la calidad de sus web. Así, para llegar a más público y posicionarse en el mercado necesitaban ofrecer páginas web de calidad; dando como resultado diversas investigaciones y estudios que arrojaron como resultado el índice IEW, que destaca características tales como: la accesibilidad; la velocidad; la usabilidad y navegabilidad; y la calidad del contenido, como principales variables que ejercen impacto sobre lo que la calidad web percibida por los usuarios.

Para la revisión de la bibliografía se han ordenado cronológicamente los artículos e investigaciones que merecieron más atención. Todo esto se detalla en un resumen elaborado en el cuadro 1, que se muestra a continuación, donde se muestran 25 autores, que han publicado en prestigiosas revistas científicas estudios que presentan investigaciones sobre factores que miden la calidad de sitios webs.

Estos trabajos van desde el año 2001, donde se encontraron las primeras investigaciones, hasta la actualidad. Todas ellas exploran aspectos como el contenido del sitio, la funcionalidad, la eficiencia y fiabilidad, la velocidad, la accesibilidad y la navegabilidad. Otros se centran más en Patrones de comportamiento deseables (Transparencia y honradez; autoridad; intimidad y protección de datos; autorización de la información; rendición de cuentas) o en la Satisfacción del usuario.

Como se puede ver el común denominador de casi todos los estudios e investigaciones se centra en cuatro apartados: accesibilidad, velocidad, navegabilidad y contenido del sitio. 


\begin{tabular}{|c|c|c|}
\hline AUTOR/ES & ESTUDIO & $\begin{array}{l}\text { CARACTERÍSTICAS DE LA CALIDAD } \\
\text { WEB }\end{array}$ \\
\hline $\begin{array}{l}\text { Buenadicha et al. } \\
2001\end{array}$ & $\begin{array}{l}\text { Un nuevo índice de evaluación web: Análisis } \\
\text { de universidades españolas. }\end{array}$ & $\begin{array}{l}\text { El contenido del sitio, la velocidad, la } \\
\text { accesibilidad y la navegabilidad. }\end{array}$ \\
\hline $\begin{array}{l}\text { Benbunan-Fich, } \\
2001\end{array}$ & $\begin{array}{l}\text { Uso de análisis de protocolo para evaluar la } \\
\text { usabilidad de un sitio web comercial. }\end{array}$ & Funcionalidad y usabilidad. \\
\hline $\begin{array}{l}\text { Miranda } \\
\text { González; Bañegil } \\
\text { Palacios, } 2004\end{array}$ & $\begin{array}{l}\text { Evaluación cuantitativa de sitios web } \\
\text { comerciales: estudio empírico de empresas } \\
\text { españolas. }\end{array}$ & $\begin{array}{l}\text { Accesibilidad, velocidad, navegabilidad, } \\
\text { contenido, funcionalidad, eficiencia y } \\
\text { fiabilidad del sitio. }\end{array}$ \\
\hline $\begin{array}{l}\text { Baños González, } \\
2004\end{array}$ & $\begin{array}{l}\text { Análisis de la competencia en las páginas web } \\
\text { de las universidades. }\end{array}$ & $\begin{array}{l}\text { Velocidad, Navegación intuitiva, Diseño, y } \\
\text { Contenido. }\end{array}$ \\
\hline $\begin{array}{l}\text { Miranda González } \\
\text { et al. } 2005\end{array}$ & $\begin{array}{l}\text { La banca por internet en España, aplicación } \\
\text { del índice de evaluación web. }\end{array}$ & $\begin{array}{l}\text { Funcionalidad, facilidad de uso eficiencia y } \\
\text { fiabilidad de la información. }\end{array}$ \\
\hline $\begin{array}{l}\text { Conesa Fuentes; } \\
\text { Paños Alvarez, } \\
2006\end{array}$ & $\begin{array}{l}\text { Evaluando la calidad de páginas web de } \\
\text { enfermería al primer clic; estudios de casos. }\end{array}$ & $\begin{array}{l}\text { Patrones de comportamiento deseables } \\
\text { (Transparencia y honradez; autoridad; } \\
\text { intimidad y protección de datos; } \\
\text { autorización de la información; rendición } \\
\text { de cuentas); accesibilidad y usabilidad. }\end{array}$ \\
\hline $\begin{array}{l}\text { Serje Schmidt, } \\
2006\end{array}$ & $\begin{array}{l}\text { Evaluación de los sitios web de los hoteles e } \\
\text { implicaciones para la gestión de marketing } \\
\text { hotelero. }\end{array}$ & $\begin{array}{l}\text { Facilidad de uso, confianza del } \\
\text { consumidor, recursos on-line y servicios } \\
\text { de relación con el usuario. }\end{array}$ \\
\hline $\begin{array}{l}\text { Moustakis; } \\
\text { Tsironis; Litos, } \\
2006\end{array}$ & $\begin{array}{l}\text { Un modelo de evaluación de la calidad del } \\
\text { sitio web. }\end{array}$ & $\begin{array}{lll}\text { Contenido; navegación; diseño } & \text { y } \\
\text { estructura; aspecto y multimedia; } & \text { y } \\
\text { singularidad. } & & \end{array}$ \\
\hline $\begin{array}{l}\text { Heitmann; } \\
\text { Lehmann; } \\
\text { Herrmann, } 2007\end{array}$ & $\begin{array}{l}\text { Elección de objetivos y toma de decisiones en } \\
\text { la satisfacción del consumidor. }\end{array}$ & Iario. \\
\hline $\begin{array}{l}\text { Miranda et al. } \\
2010\end{array}$ & $\begin{array}{l}\text { Evaluación cuantitativa de los sitios web de } \\
\text { fútbol: una evaluación empírica. Estudio del } \\
\text { mejor club de fútbol europeo. }\end{array}$ & $\begin{array}{l}\text { Accesibilidad, velocidad, navegabilidad y } \\
\text { contenido del sitio. }\end{array}$ \\
\hline $\begin{array}{l}\text { Lee; Koubek, } \\
2010\end{array}$ & $\begin{array}{l}\text { Los efectos de la usabilidad y los atributos de } \\
\text { diseño web en la preferencia de los usuarios en } \\
\text { sitios web de comercio electrónico. }\end{array}$ & Us \\
\hline Pei; Jiao, 2010 & stigación de diseño de usabili & Usa \\
\hline $\begin{array}{l}\text { Woodside; Dion, } \\
2010\end{array}$ & $\begin{array}{l}\text { Utilidad de los Sitios Web de Gobierno y de } \\
\text { Destino Privado }\end{array}$ & $\begin{array}{l}\text { Disponibilidad de información; y utilidad y } \\
\text { valor de la información en los sitios web. }\end{array}$ \\
\hline $\begin{array}{l}\text { González-Soltero } \\
\text { et al. } 2010\end{array}$ & $\begin{array}{l}\text { Análisis del contenido, posicionamiento y } \\
\text { calidad de páginas web de nutrición y } \\
\text { trastornos de la conducta alimentaria }\end{array}$ & $\begin{array}{l}\text { Transparencia y ausencia de conflicto de } \\
\text { intereses; autoría; protección de datos } \\
\text { personales; } \quad \text { responsabilidad r y } \\
\text { accesibilidad. }\end{array}$ \\
\hline $\begin{array}{l}\text { Rodríguez- } \\
\text { Martínez, Codina; } \\
\text { Pedraza-Jiménez, } \\
2012\end{array}$ & $\begin{array}{l}\text { Indicadores para la evaluación de la calidad en } \\
\text { cibermedios: análisis de la interacción y de la } \\
\text { adopción de la Web } 2.0\end{array}$ & $\begin{array}{l}\text { Adaptación del medio de comunicación a } \\
\text { la interacción de la Web 2.0; Arquitectura } \\
\text { de la información; Usabilidad; } \\
\text { Accesibilidad; Calidad del contenido web. }\end{array}$ \\
\hline
\end{tabular}


Continuação...

\begin{tabular}{|c|c|c|}
\hline $\begin{array}{l}\text { González López } \\
\text { et al. } 2013\end{array}$ & $\begin{array}{l}\text { El índice cuantitativo de calidad web como } \\
\text { instrumento objetivo de medición de la calidad } \\
\text { de sitios web corporativos. }\end{array}$ & 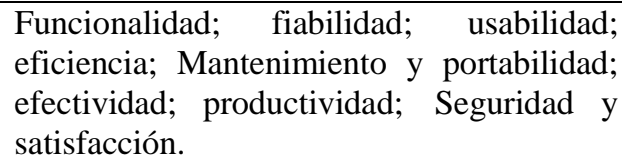 \\
\hline $\begin{array}{l}\text { Fernández-Cavia } \\
\text { Vinyals Mirabent; } \\
\text { López Pérez, } 2013\end{array}$ & $\begin{array}{l}\text { Calidad de los sitios web turísticos oficiales de } \\
\text { las comunidades autónomas españolas. }\end{array}$ & $\begin{array}{ll}\text { Arquitectura de } & \text { la información, } \\
\text { posicionamiento, } & \text { usabilidad } \\
\text { accesibilidad. } & \end{array}$ \\
\hline $\begin{array}{l}\text { Grávalos Macho, } \\
2013\end{array}$ & $\begin{array}{l}\text { La calidad de una página web como } \\
\text { herramienta de comunicación. }\end{array}$ & $\begin{array}{l}\text { Accesibilidad, usabilidad, contenido, } \\
\text { diseño web y posicionamiento. }\end{array}$ \\
\hline Buckland, 2013 & La calidad de la información web. & Fiabilidad y coherencia de la información. \\
\hline $\begin{array}{l}\text { Díaz-Luque; } \\
\text { Jiménez Marín, } \\
2013\end{array}$ & $\begin{array}{l}\text { Marcas de destino y evaluación de sitios web: } \\
\text { una metodología de investigación. }\end{array}$ & 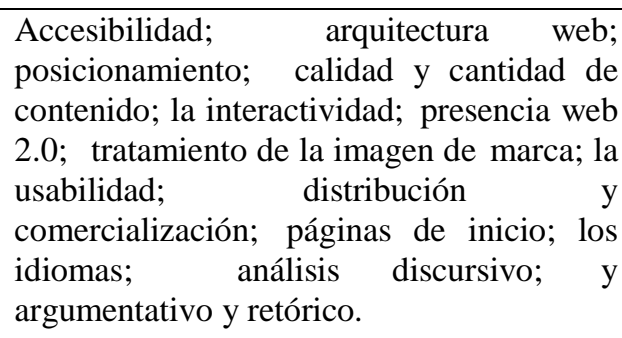 \\
\hline $\begin{array}{l}\text { Rodríguez } \\
\text { Rangel; Sánchez } \\
\text { Rivero, } 2014\end{array}$ & $\begin{array}{l}\text { Análisis de las páginas web de los espacios } \\
\text { naturales como destinos Turísticos a través del } \\
\text { modelo de Basch: una aplicación al caso de } \\
\text { Rusia. }\end{array}$ & Indicadores dicotómicos. \\
\hline $\begin{array}{l}\text { De la Torre et al. } \\
2014\end{array}$ & $\begin{array}{l}\text { Evaluación de la calidad de las páginas webs } \\
\text { de los hospitales del Sistema Sanitario Público } \\
\text { de Andalucía. }\end{array}$ & Accesibilidad y usabilidad \\
\hline $\begin{array}{l}\text { Miranda; Rubio; } \\
\text { Chamorro, } 2015\end{array}$ & $\begin{array}{l}\text { Una metodología de evaluación para los sitios } \\
\text { web del hotel: aplicación a los } 10 \text { principales } \\
\text { destinos de ciudades en el mundo. }\end{array}$ & $\begin{array}{l}\text { Visibilidad, velocidad, navegabilidad } \mathrm{y} \\
\text { contenido }\end{array}$ \\
\hline $\begin{array}{l}\text { Fernández-Cavia; } \\
\text { Castro, } 2015\end{array}$ & $\begin{array}{l}\text { Comunicación y branding en los sitios web } \\
\text { nacionales de turismo. }\end{array}$ & $\begin{array}{l}\text { Aspectos técnicos aspectos comunicativos } \\
\text { y aspectos persuasivos. }\end{array}$ \\
\hline $\begin{array}{l}\text { De Oliveira- } \\
\text { Arruda; Gondim- } \\
\text { Nogueira, Dutra- } \\
\text { Dias, } 2015\end{array}$ & $\begin{array}{l}\text { Importancia relativa de Factores de Calidad y } \\
\text { determinantes en la Selección de Cursos de } \\
\text { Lengua Extranjera en Redes Sociales. }\end{array}$ & $\begin{array}{l}\text { La calidad de la información, calidad del } \\
\text { sistema, y calidad específica del vendedor. }\end{array}$ \\
\hline Corrêa, 2012 & $\begin{array}{l}\text { Análisis de las estrategias de marketing } \\
\text { adoptadas por EMBRATUR en el portal } \\
\text { Braziltour.com }\end{array}$ & $\begin{array}{l}\text { Contenido informativo, capacidad de } \\
\text { comercialización y distribución, canales de } \\
\text { comunicación interactivos usados y } \\
\text { versiones del portal en diferentes idiomas. }\end{array}$ \\
\hline
\end{tabular}

\section{3 ÍNDICE DE CALIDAD WEB: FACTORES DE MEDICIÓN}

A continuación, se detallarán los factores de medición que permitieron elaborar un índice de calidad web de los hoteles estudiados. 


\subsection{HERRAMIENTA DE EVALUACIÓN WEB: IEW}

La herramienta que se utilizó para medir la calidad web de las páginas de los hoteles de 5 estrellas fue IEW. Como se puede observar en la Imagen 1, este índice ha sido utilizado ya, por diversos autores, para medir la calidad de los sitios webs.

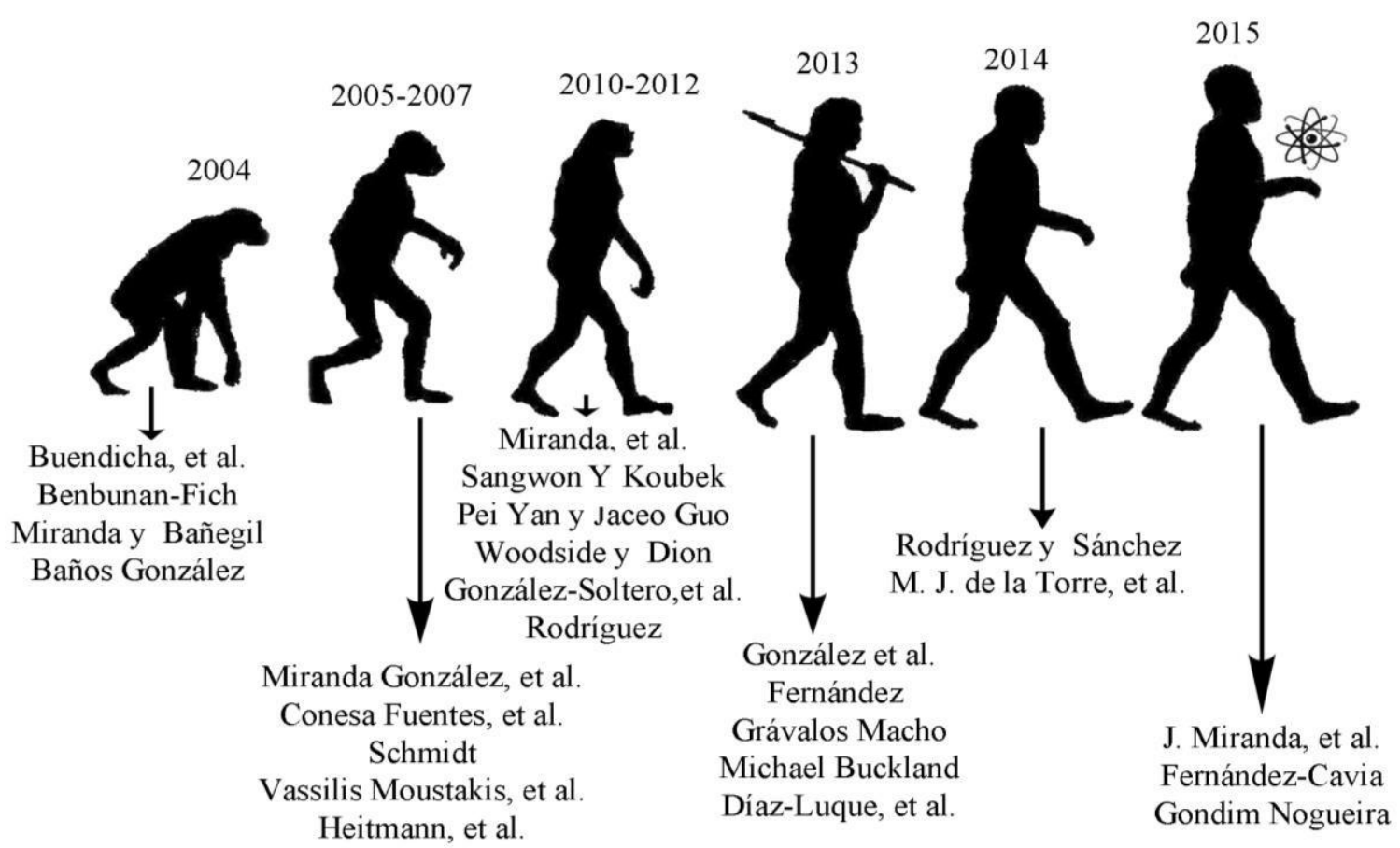

\footnotetext{
IMAGEN 1 - EVOLUCIÓN DEL USO DEL ÍNDICE DE LA CALIDAD WEB FUENTE: Elaboración propia
}

IEW se basa en 4 factores fundamentales para medir la calidad de las páginas web, que en concreto son: Accesibilidad, navegabilidad y usabilidad, velocidad, y calidad de contenido. En la imagen1, se recoge la evolución de dicho índice.

\subsection{ACCESIBILIDAD}

Según Murray (1997), es posible medir la calidad de un sitio web, si éste es fácilmente identificable y accesible a los usuarios. Pero, sólo el número de "clicks" en una página no puede considerarse una medida exacta de la calidad o el éxito de un sitio web. 
La medida más usual es el número de impactos generados. Sin embargo, también se producen problemas de exactitud en este sentido, porque si una página contiene gráficos, cada gráfico es contabilizado como un nuevo impacto y hay métodos para incrementar el número de impactos. De forma que el total de impactos no refleja necesariamente el número real de visitas a la página (MURRAY, 1997).

Esta necesidad de aumentar la precisión, conduce a la idea de que la valoración real de un sitio web con objetivos medibles, precisa que estos sean definidos (MIRANDA-GONZÁLEZ, 2004). Por lo cual, se pueden emplear dos factores para medir esta categoría: presencia en el motor de búsquedas y popularidad de los enlaces. Mayor posicionamiento en los motores de búsqueda se traduce en un mayor tráfico de un sitio y por lo tanto, aumentan su grado de accesibilidad.

Las ventajas de un elevado número de enlaces dirigidos a una página son evidentes: en primer lugar, cuanto mayor sea el número de páginas que enlazan con la que está siendo objeto de estudio, mayor cantidad de tráfico es susceptible de ser recibido, y, en segundo lugar, los motores de búsqueda ubicarán la página en una posición más alta cuantos más enlaces se dirijan a la referida página (MIRANDA; BAÑEGIL, 2004).

En resumen, se puede considerar que los aspectos de la página que se deben evaluar son los siguientes: 1 - La presencia en motores de búsqueda: introducir el nombre del hotel (como es el caso) en Google y comprobar si la dirección web aparece entre los 10 primeros; 2 - La Popularidad de los enlaces: se estudiará a través de "Open Site Explorer" de un sitio web. En este caso, de la salud de un dominio, su credibilidad y autoridad, introduciendo la dirección web de la página en esta herramienta se obtiene una calificación para cada página.

\subsection{VELOCIDAD}

La segunda dimensión se corresponde con la velocidad, la cual se medirá por medio de bytes. El tiempo en que la página principal se carga por completo estará relacionado con su tamaño, por lo que, una página de inicio más corta implicará un acceso más rápido (BUENADICHA et al., 2001).

\footnotetext{
${ }^{1}$ https://moz.com/researchtools/ose/
} 
Según Hoffman y Novak (1996), la velocidad de acceso y el tiempo de respuesta son variables muy significativas porque el tiempo es un factor crítico. Varios estudios validan que hay una correlación significativa entre la velocidad de descarga de una página y la satisfacción de los usuarios. De igual forma, Miranda González y Bañegil Palacios (2004) consideran que el tiempo de respuesta es una variable muy significativa ya que es un factor crítico para el visitante de un sitio web y constatan que como norma general, las páginas cuyo contenido descarga con rapidez, son de fácil navegación.

La velocidad de carga de las páginas de las cadenas hoteleras se va a analizar usando Page Speed Insight de Google Developers, diseñado para evaluar y optimizar sitios y páginas $w^{2} b^{2}$.

\subsection{NAVEGABILIDAD Y USABILIDAD}

En un principio, IEW sólo consideraba a la navegabilidad, sin embargo, más tarde la usabilidad ha sido añadida ya que juega un papel relevante en el análisis y ha sido considerada en estudios de otros sectores (CONESA FUENTES; PAÑOS ALVAREZ, 2006).

\subsubsection{Navegabilidad}

Un diseño inadecuado de la web puede generar consecuencias no deseadas, como una pérdida potencial de ventas en la medida en que los usuarios no consigan encontrar lo que desean o una pérdida potencial de visitas repetidas debido a la experiencia inicial negativa de los usuarios.

En este sentido, se puede afirmar que para que una web sea de calidad, el usuario nunca debe sentirse perdido dentro de la misma, es decir cada página debe ser autosuficiente y proporcionar enlaces a la página principal. Los factores utilizados en diversos trabajos para evaluar esta categoría son los siguientes: existencia permanente de un menú del sitio que permita un acceso rápido a las diferentes secciones de cada página y número de clics necesarios para el acceso la información pertinente del sitio web.

\footnotetext{
${ }^{2}$ https://developers.google.com/
} 
Según Moustakis; Tsironis; Litos (2006) (citando a KANERVA et al., 1997³ , p. 25; BORGES; MORALES; RODRIGUEZ, $1998^{4}$, p. 26) se plantea un primer interrogante sobre la navegación: ¿Están las direcciones para el uso del sitio web facilitadas?, la navegación refleja el soporte facilitado a los usuarios cuando se mueven dentro y alrededor del sitio web. Los elementos de navegación incluyen: facilidad de movimiento, facilidad para entender la estructura del sitio, disponibilidad y validez de los enlaces. Por ejemplo, aumentando el número de enlaces a sitios no necesariamente se añade valor al sitio. Además, los enlaces deberían ser periódicamente revisados y evitar un exceso de enlaces, ya que la existencia de enlaces que no funcionan resta calidad a cualquier web.

Los factores utilizados para evaluar esta categoría (MIRANDA; BAÑEGIL, 2004) son los siguientes: Menú permanente que permite un rápido acceso a las diferentes secciones desde cada página, y función de búsqueda por palabras clave, que permita a los usuarios localizar información disponible en el interior de la página de la empresa.

\subsubsection{Usabilidad}

Según Buenadicha et al. (2001), la usabilidad es como de bien y como de fácil un usuario sin formación ni entrenamiento previo, puede interactuar con un sistema de información o una página web.

Si se prefieren definiciones aún más formales para el concepto de usabilidad, se podrían mencionar las siguientes:

. Según ISO/IEC 9126: "la usabilidad se refiere a la capacidad de un software de ser comprendido, aprendido, usado y ser atractivo para el usuario, en condiciones específicas de uso".

. Según ISO/IEC 9241: “Usabilidad es la eficacia, eficiencia y satisfacción con la que un producto permite alcanzar objetivos específicos a usuarios específicos en un contexto de uso específico.

\footnotetext{
${ }^{3}$ KANERVA, A.; KEEKER, K.; RISDEN, K.; SCHUH, E.; CZERWINSKI, M. Web usability research at Microsoft Corporation. Human Factors for World Wide Web Development, Lawrence Erlbaum, New York, United States of America, 1997.

4 BORGES, J. A.; MORALES, I.; RODRIGUEZ, N. J. Page design guidelines developed through usability testing. Human factors and Web development, p. 137-152, 1998.
} 
Por otra parte también se observan otras definiciones hechas por otros autores, como la planteada por Islam; Bouwman (2016, p. 1):

\begin{abstract}
La parte fundamental de la usabilidad de un sitio web está determinada por los signos gráficos que representan elementos de control y medida para los usuarios y les proporcionan referentes visuales relacionados a elementos que se encuentran en su vida cotidiana y que al interactuar con ellos en el sitio web les permite con facilidad comprenderlo y utilizarlo. Los signos gráficos pueden ser imágenes, botones, menús de navegación, entre otros.
\end{abstract}

Básicamente la usabilidad se refiere al grado en como el usuario y el sistema se pueden "comunican" claramente y sin mal entendidos dentro de la interface. Nielsen (2003) define la usabilidad como una medida de la calidad de la experiencia del usuario cuando interactúa con web o una aplicación de software tradicional, y especifica cinco características: facilidad de aprendizaje, eficiencia de uso, memoria o facilidad de recordarla, frecuencia de error y satisfacción subjetiva.

Un sitio Web que presente alguna barrera de usabilidad (ACERA, 2012), es decir, que haya algo difícil de utilizar o hacer o entender, verá reducidos sus logros y la consecución de los objetivos para los que se diseñó dicho sitio web.

\title{
3.5 CALIDAD DEL CONTENIDO
}

La cuarta dimensión de IEW se refiere a la calidad del contenido del sitio web, donde se evalúa la presencia de información relevante para los usuarios. Buenadicha et al. (2001) sugieren que un sitio debe tener contenidos que satisfagan las necesidades de los usuarios y debe actualizarse al menos cada mes.

La calidad del contenido de la página se medirá evaluando la presencia de información relevante para los usuarios como ya se ha dicho. Una página deberá contener información que satisfaga las necesidades de los usuarios y deberá ser actualizada como mínimo con una periodicidad mensual. Del mismo modo, la inclusión de fechas en artículos, notas de prensa y todo tipo de información resulta de gran interés para no generar confusión en los usuarios (NIELSEN, 2003; MIRANDA GONZÁLEZ; BARRIUSO IGLESIAS; CORTÉS GÓMEZ, 2005).

Un estudio realizado por Rubio Lacoba; Miranda González; Chamorro Mera (2006) recoge para el sector logístico los objetivos de las organizaciones de una web 
desde el punto de vista de los contenidos: objetivo informativo, dirigir información al mercado; objetivo transaccional, realizar transacciones; y objetivo de comunicación, servir como una herramienta de mejora de la relación con los clientes.

El contenido también se refiere a la capacidad de respuesta de una página web para satisfacer una petición de usuario y a la veracidad sobre la información, la cual se incluye en el sitio (BECK, 2005; ZHU; GAUCH, 2000).

Por último, el subcriterio específico que captura la confianza es utilidad del contenido. Este es medido a través de la diligencia, la comprensión, la integridad y el lenguaje de la información proporcionado a los usuarios para respaldar el contenido (VORA, 1998). Finalmente, el otro subcriterio es la fiabilidad, que implica que el contenido debe ser modificado, corregido y mejorado continuamente para reflejar los cambios del entorno (ISO, 1998a, 1998b).

\subsubsection{Contenido informativo}

La categoría de contenido informativo en una web tiene como finalidad presentar a los visitantes de la web información diversa o concreta, enfocada al propósito o temas de del sitio web. De acuerdo con Miranda González; Barriuso Iglesias; Cortés Gómez (2005), el contenido informativo, puede incluir información referida a la organización de la empresa, socios, clientes destacados y políticas sociales.

\subsubsection{Contenido transaccional}

Dentro de este apartado se han analizado los siguientes ítems: Forma en que se realizan las reservas, Herramienta de búsquedas, Check-in on line y Medios de pago.

\subsubsection{Contenido comunicativo}

Las redes sociales pueden definirse como herramientas de comunicación basadas en la tecnología web. Son a su vez estructuras organizadas en torno a perfiles personales o profesionales de los usuarios y su objeto es formar comunidades de suscriptores, tales como individuos u organizaciones los cuales están relacionados de acuerdo a algún criterio (categorías, grupos, relación profesional, amistad, parentesco, etc.) ligado a la 
personalidad o profesión de los mismos (CASTAÑEDA; GUTIÉRREZ, 2010). Normalmente estos miembros publican en el foro usuario del sitio web del hotel.

Dentro de este apartado se localizan los siguientes ítems:

- Email de contacto: Correo de la empresa recogido en la web.

- Dirección o teléfono: dirección y teléfonos del hotel recogidos correctamente en la web.

- Boletín electrónico o newsletter: es una publicación digital más bien informativa que se distribuye a través del correo electrónico con cierta periodicidad (diaria, semanal, mensual, bimensual o trimestral). Normalmente contienen artículos de interés sobre la marca y del ámbito en que la misma se desenvuelve. Los que reciben este tipo de comunicaciones son suscriptores que previamente han mostrado interés en la marca y han solicitado recibir información por correo.

- Atención al cliente para incidencias.

- Dejar opiniones y conocer opiniones.

- Enlaces a Fan page propias en Redes sociales: Facebook, Twitter, YouTube, Pinterest, Vimeo, Flickr, Linkedin, Instagram o Google+, entre otras.

\section{METODOLOGÍA Y DISEÑO DE LA MUESTRA}

Para efectuar el presente estudio, se usó el motor de reservas online "Booking", para localizar los hoteles que fueran objeto del análisis, en este caso exclusivamente los hoteles de 5 estrellas de Madrid, descartando a todos aquellos que no cumplieran los requisitos de "singularidad", es decir, excluyendo a aquellos hoteles que no contaran con una formato web distinto a los de otros hoteles de la misma cadena obtenidos en la búsqueda.

Por otra parte, se procedió a analizar cada uno de los hoteles escogidos por medio del método IEW, por el cual se obtuvieron determinadas puntuaciones para cada uno de éstos. Después de ser obtenidas las puntuaciones referentes al IEW para cada hotel, se procedió a representar gráficamente cada categoría del índice, para su posterior análisis.

El primer paso fue realizar una búsqueda del censo de hoteles y filtrar las búsquedas a través de booking.com, para conocer la opinión de las personas que se han alojado anteriormente en los hoteles. 
Se realizó la búsqueda concretamente para el mes de julio del 2016, indicando las especificaciones con las que se deseaba contar en los hoteles, las cuales no son otras que la categoría (5 estrellas) y la ubicación (Madrid) de los mismos.

Por otro lado, en este estudio solo fue evaluada una web por hotel, a pesar de haberse obtenido como resultado en la búsqueda más de un hotel por cadena. En dichas webs se observaron plantillas y formatos iguales, por lo cual fueron descartadas las webs de los hoteles de una misma cadena cuyo sitio web tuviera las mismas características o la misma interfaz que otra web de la misma cadena.

Tras una búsqueda exhaustiva, se obtuvieron 26 hoteles pertenecientes a 10 cadenas hoteleras. Sin embargo, tras haberse comprobado que existían coincidencias en algunas de las webs analizadas, en concreto respecto a la similitud de sus plantillas, la muestra final se vio reducida a 20 establecimientos hoteleros.

\section{ANÁLISIS Y RESULTADOS}

A continuación se presentan el análisis llevado a cabo y los resultados obtenidos como consecuencia del mismo.

\subsection{RESULTADOS PARA LA ACCESIBILIDAD}

Respecto a la accesibilidad web, en primer lugar se analizó la presencia de las webs tratadas en los principales motores de búsqueda. En el caso de este análisis se ha utilizado como motor de búsqueda al buscador Google Chrome para localizar las webs de hoteles. Tras la búsqueda individualizada, se ha obtenido un $100 \%$ de presencia web, por lo cual no se considera relevante incluir una gráfica de esta característica, ya que no es un rasgo distintivo, y por ende no diferenciará a unas webs respecto a otras.

En segundo lugar para este apartado, se procedió a identificar en qué posición se encontraban cada una de las webs en los motores de búsquedas, sabiendo que en este análisis se analizó la posición que ocupó cada web respecto a una escala comprendida entre la posición 1 a la 10, siendo la 1 la posición más alta y la 10 la más baja. 
Como se puede apreciar en la gráfica 1, 19 de las webs analizadas se ubican en la primera posición en los motores de búsqueda (95\%), y únicamente 1 hotel, se encontró en una posición distinta (5\%), teniendo tal hotel la segunda posición, lo cual, sin embargo, no fue para nada negativo en el caso de referirse a un acertado posicionamiento web.

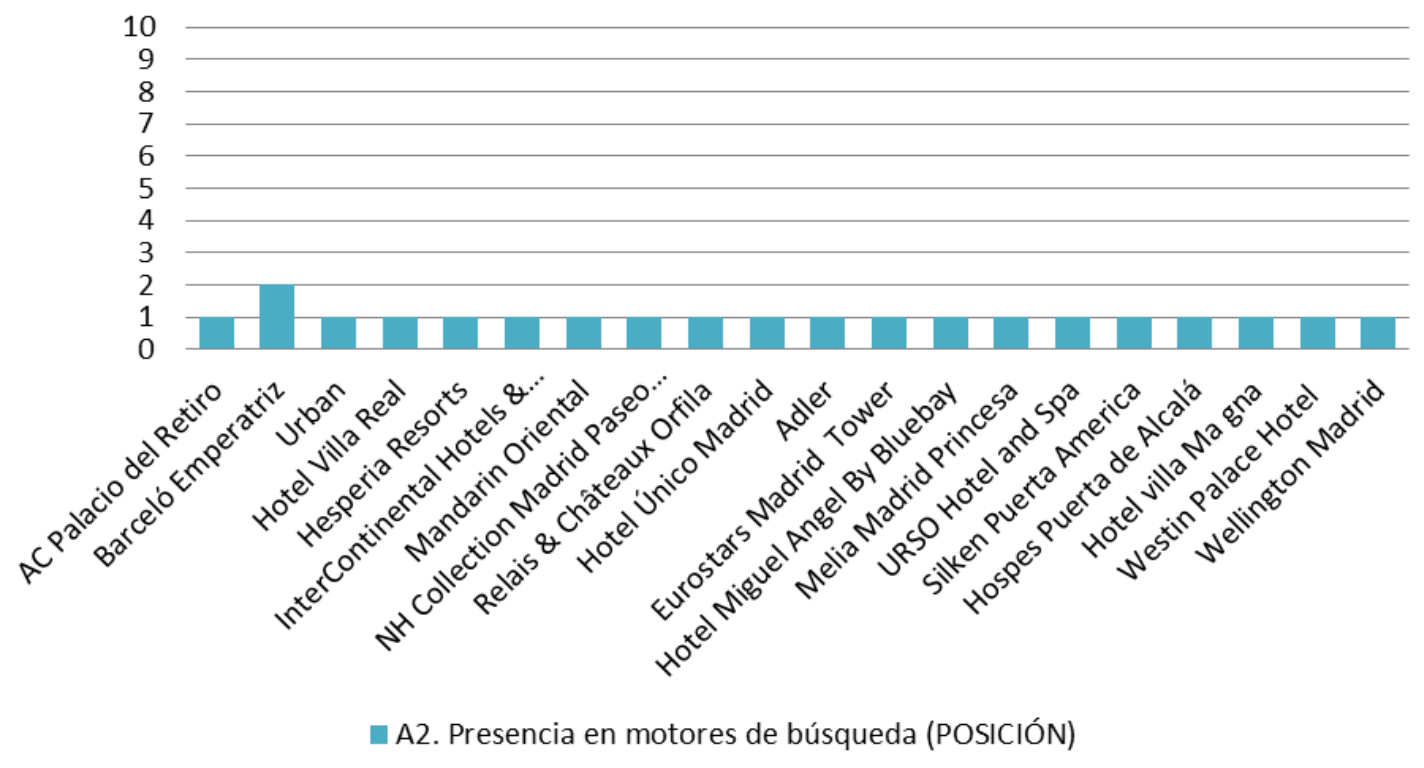

GRÁFICA 1 - POSICIÓN DE LOS HOTELES EN LOS MOTORES DE BÚSQUEDA FUENTE: Elaboración propia

Por último para este apartado, se encuentra el análisis de la popularidad de las webs (GRÁFICA 2). En este caso es posible apreciar que los hoteles con menores índices de popularidad fueron el Hotel Villa Real, el Hotel Mandarín Oriental y el Hotel Único Madrid, los cuales se encontraron en un índice de 0/100, la cual es una puntuación más que negativa respecto a los demás, los cuales poseen valores más normales y variados, siendo los más positivos el de los hoteles AC Palacio del Retiro, Meliá Princesa y Silken puerta de América. 


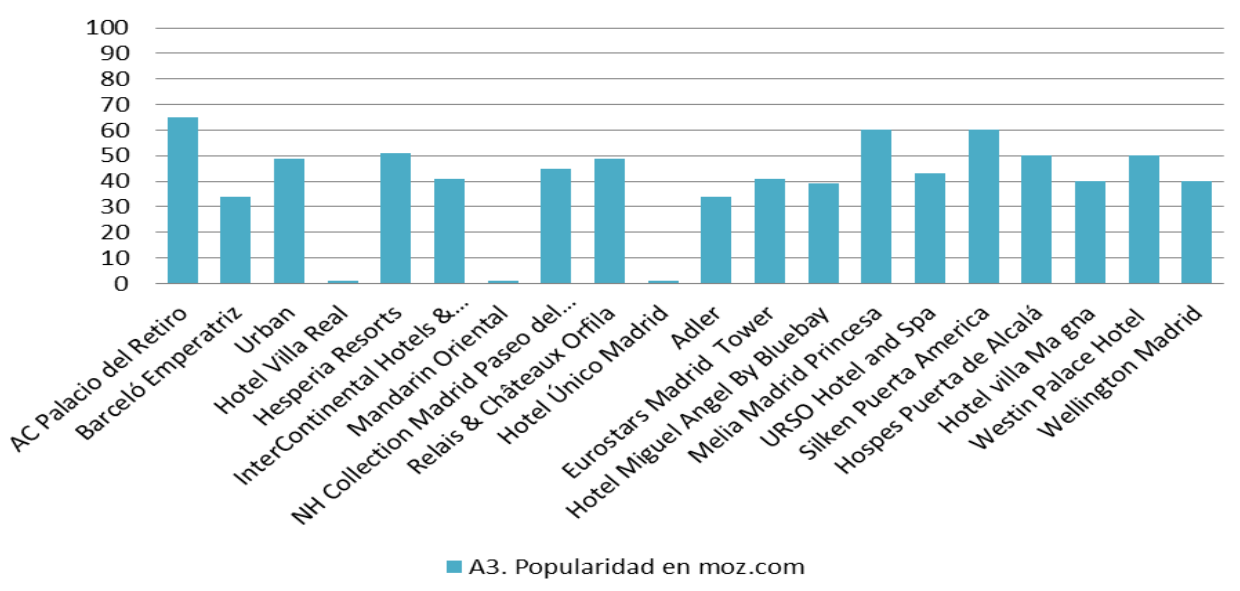

GRÁFICA 2 - POPULARIDAD DE LAS WEBS EN OPEN SITE EXPLORER FUENTE: Elaboración propia.

\subsection{RESULTADOS PARA LA NAVEGABILIDAD Y USABILIDAD}

Con relación a la navegabilidad y la usabilidad de las webs analizadas, se puede decir que tras un análisis, se obtuvieron datos generales muy positivos tal y como se expone a continuación (GRÁFICA 3).

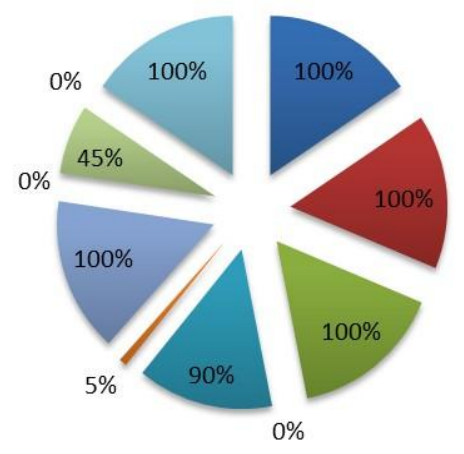

\footnotetext{
N1. Lenguaje simple y claro

- N2. Página donde la navegación es sencilla

n3. Interfaz amigable

N4. Existencia de enlaces que no funcionan

n5. Dinamismo de la web

n6. Ayuda en línea

- N7. Página adaptada a dispositivos móviles

- N8. Página adaptada a personas con discapacidad

N9. NAVEGABILIDAD [Mapa o índice del sitio web]

N9. NAVEGABILIDAD [Función de búsqueda de

palabras clave]

N9. NAVEGABILIDAD [Menú permanente ]
}

\section{GRÁFICA 3 - NAVEGABILIDAD Y USABILIDAD}

FUENTE: Elaboración propia

20 de los hoteles contaron con un tipo de lenguaje considerado como simple y claro (100\%), lo cual facilitó el uso a los usuarios; se observaron, además, páginas donde la navegación es considerada como sencilla con un interfaz amigable con el usuario, no contenían enlaces que no funcionaran, estando adaptadas a los dispositivos móviles y contando, en su totalidad, con menú permanente. 
18 webs contaban con un buen nivel de dinamismo web (90\%). En cuanto al mapa web, se puede decir que solo 9 de los hoteles poseía esta característica (45\%), a pesar de que este mapa clasifica las informaciones por temáticas, fechas, suplementos, herramientas o servicios; lo cual facilita en gran medida la navegabilidad de los usuarios dentro de la web, por este motivo las páginas deberían de tomar dicha característica un poco más en consideración.

Por otra parte, ningún sitio web de hoteles analizados, contaba con adaptación a personas discapacitadas, lo cual hace a la web menos o nula como navegable y usable para este tipo de usuarios. Así también, ningún hotel contaba con función de búsqueda de palabras clave, lo cual quizá haga a las webs menos sencillas desde un punto de vista orientado a la comodidad del usuario.

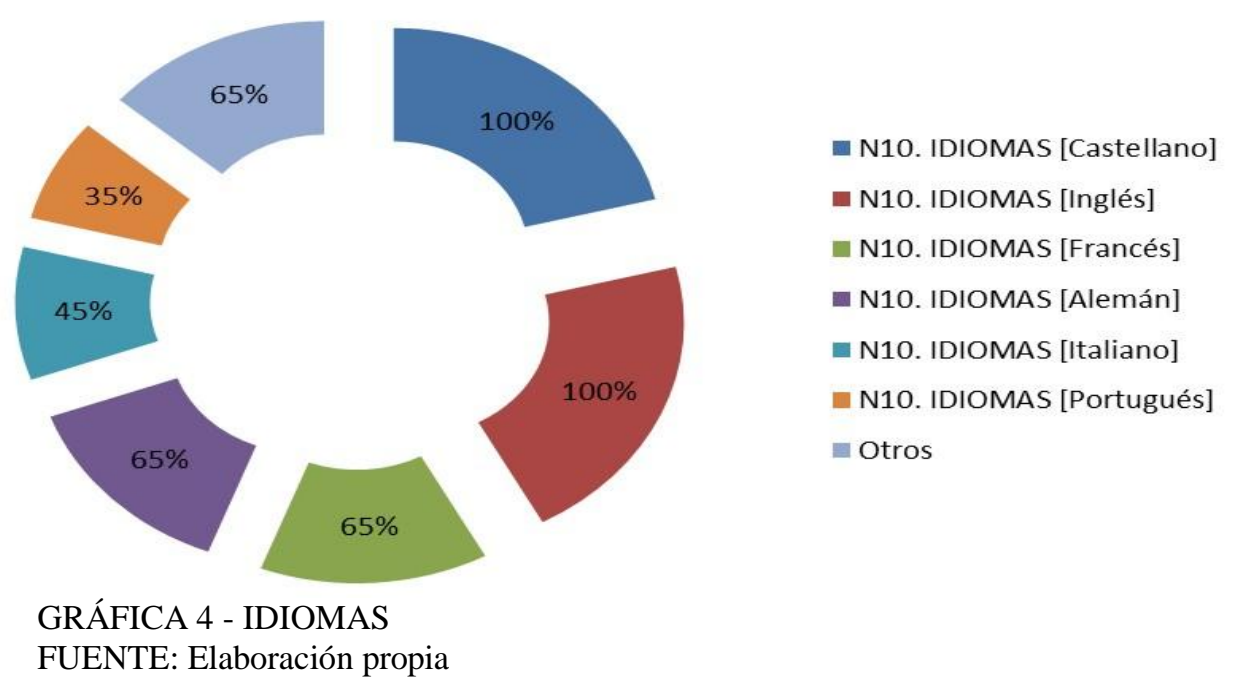

Por otro lado, en este apartado se ubica el sub-criterio denominado "idiomas" (GRAFICA 4), en el cual el castellano y el inglés como es lógico para las webs de hoteles situados en España, obtienen las mejores puntuaciones, conociéndose que todas las webs incluían dichos idiomas. Sin embargo, en el caso del francés y el alemán, solo un 13 páginas los incluyeron (65\%); 9 incluyeron el italiano (45\%) y solo 7 el portugués (35\%). Todo esto se puede apreciar en la gráfica 4.

Así, existían webs que incluían además de todos o algunos de los idiomas mencionados anteriormente, otros como el ruso con un total de $11(55 \%)$, chino con 8 (40\%), japonés con 6 (30\%); mientras que se observaron otros idiomas con menos presencia, como es el caso del holandés con 3 (15\%), el coreano con $2(10 \%)$, y el árabe con una 1 web (5\%), tal y como se aprecia en la gráfica 5. 


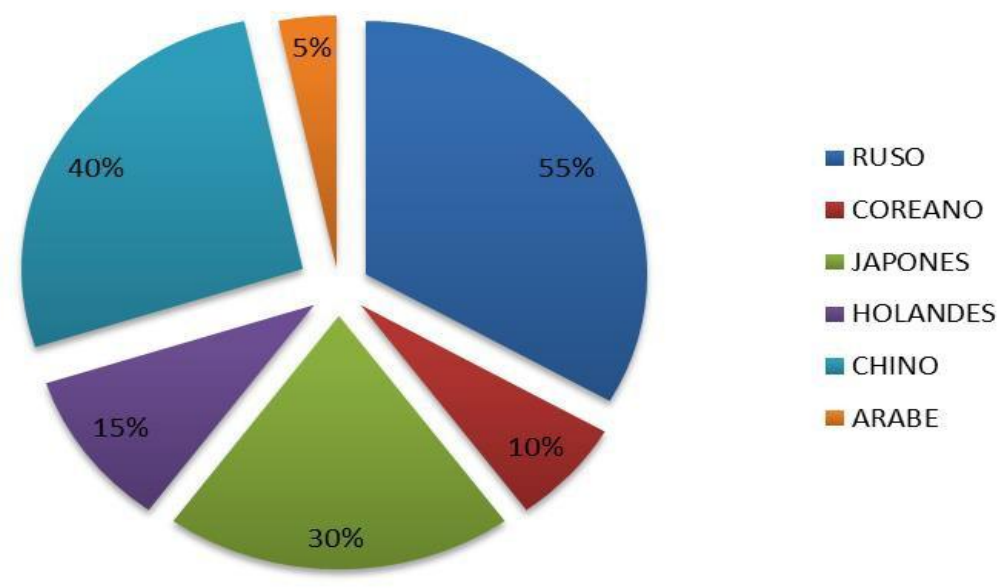

GRÁFICA 5 - OTROS IDIOMAS

FUENTE: Elaboración propia

\subsection{RESULTADOS PARA LA VELOCIDAD}

En cuanto a la velocidad, la mayoría de las webs de los hoteles analizados contaban con valores por encima del nivel medio, encontrando solamente a los hoteles “AC Palacio del Retiro", "Barceló Emperatriz", "Hesperia Resorts”, y con "Relais \& Châteaux" con valores por debajo de dicho nivel y con el hotel "InterContinental" con el valor más bajo, siendo éste el último. Se pueden apreciar dichas puntuaciones en la gráfica 6 , expuesta a continuación.

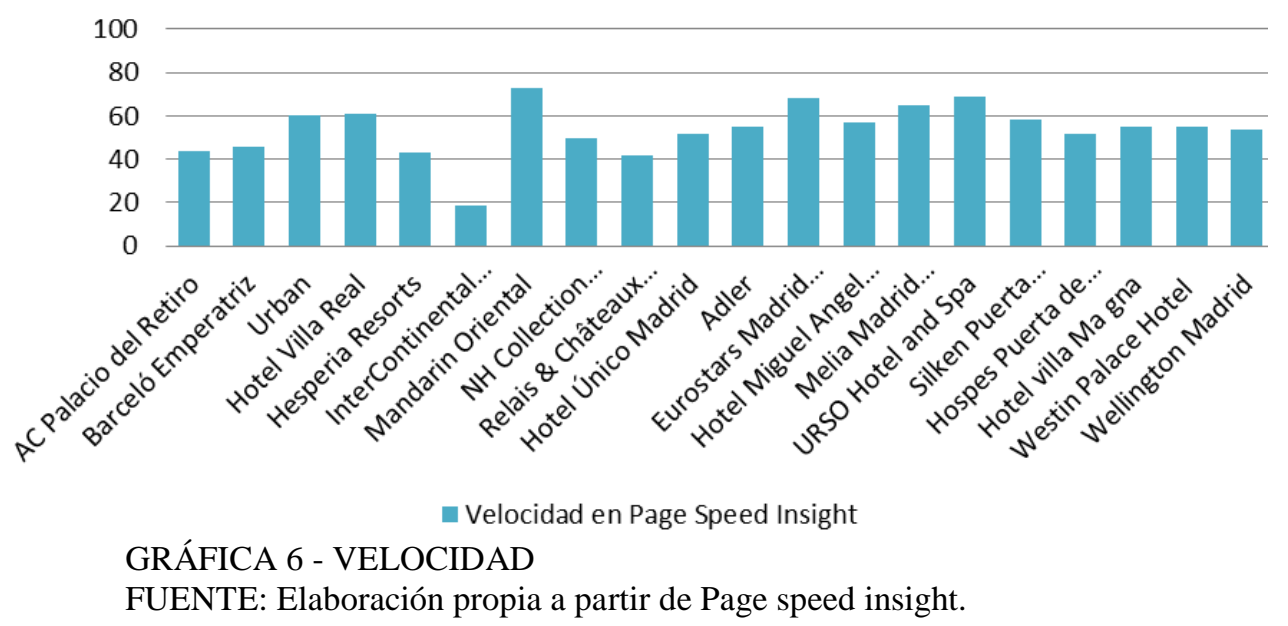

En relación a las medidas correctivas que la herramienta Page Speed Insight sugiere, para que las webs de los hoteles aumenten su velocidad, se destacan: Eliminar o minificar JavaScript (el cual bloquea la visualización) y el CSS del contenido de la 
mitad superior de la página; especificar el caché del navegador; priorizar el contenido visible; optimizar imágenes; y minificar HTML.

\subsection{RESULTADOS PARA LA CALIDAD DEL CONTENIDO}

En este apartado se conocerán los resultados de manera individualizada de cada una de las sub-categorías de la calidad del contenido, para de esta manera tener un acercamiento más cercano a ésta.

5.4.1 Resultados para el apartado de contenido informativo

Se analizó el contenido informativo de las webs; dicho contenido versa sobre diversos ítems, en los cuales se obtuvieron valores muy diversos tal y como se expone continuación en la gráfica 7.

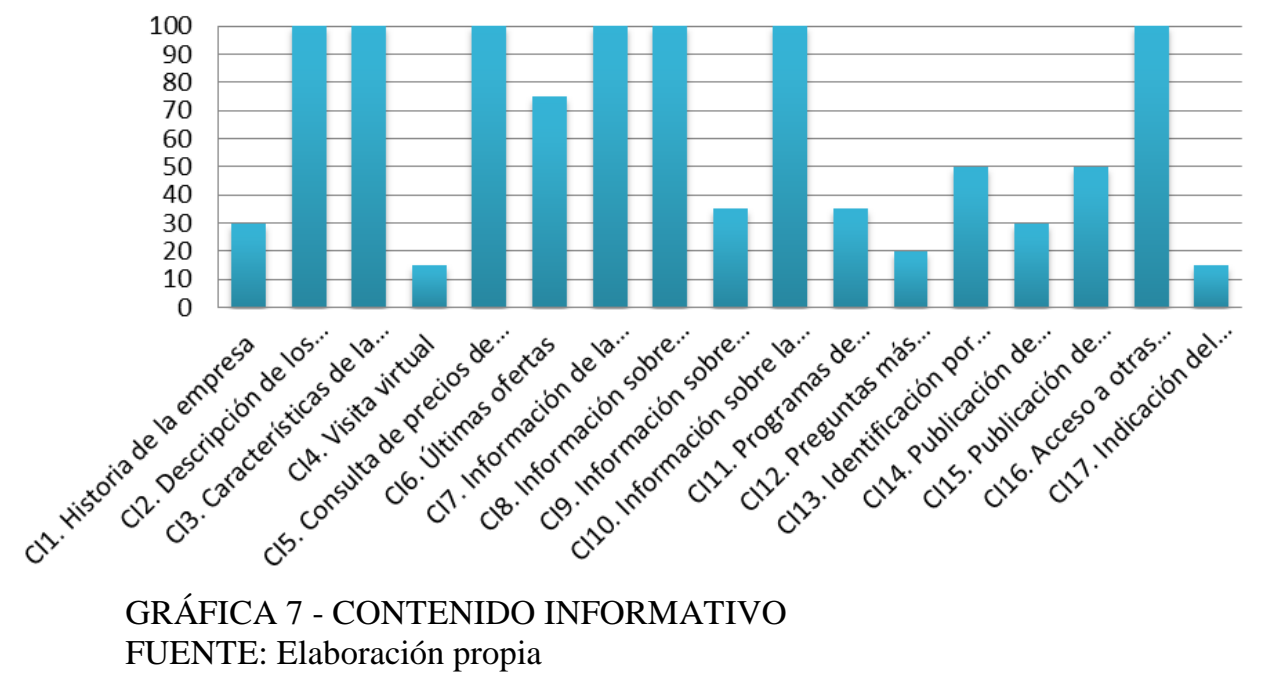

Con relación a la descripción de los servicios ofrecidos, la posibilidad de consultar los precios de dichos servicios, la información de la política de cancelación de las reservas, la información sobre seguridad en las transacciones que se realizaban en la web y las características de la habitación, todos los hoteles ofrecieron esta información en sus webs. Por otro lado, solo 15 de los hoteles ofrecían en sus webs la posibilidad de poder conocer las últimas ofertas. 
En cuanto a los programas de fidelización, tan solo 7 hoteles disponían de esta opción, y las webs que facilitaban dicha funcionalidad, hacían sentir especiales a los clientes de alguna manera u otra, ya que algunos hoteles brindaban muchas más facilidades a este tipo de clientes, tales como el check-in anticipado por medio del móvil o la posibilidad de ir acumulando puntos canjeables por estancias futuras, como es el caso de la fidelización de los hoteles NH por medio de la fidelización "NH Reward".

Sobre las preguntas más frecuentes "FAQs", solo 2 hoteles disponían de este apartado; y sobre la identificación por tipos de usuarios, 10 hoteles contaban con esta posibilidad, siendo este dato muy distinto al de fidelización como tal, ya que algunos de los hoteles contaban con la posibilidad de identificación por tipos de usuarios para otras empresas pero no para usuarios en sí.

Solo 7 webs disponían de información sobre la política de calidad y medio ambiente. De cara a la publicación de noticias de actualidad, solo 6 hoteles contaban con ese apartado, siendo este tipo de noticias mayormente las referidas al ocio y la cultura, concretamente a cerca de los espectáculos previstos en la ciudad, tales como conciertos, representaciones teatrales, entre otros. Y con respecto a la historia de la empresa, solo 6 hoteles informaban en sus webs.

En cuanto a la posibilidad de realizar una visita virtual al hotel, exclusivamente 3 hoteles disponían de tal posibilidad, lo cual es una cantidad muy baja. En relación a la publicación de ofertas de trabajo, la mitad de las webs de los hoteles ofrecían dicha "sección", dando a los posibles aspirantes la posibilidad de acceder a las vacantes o enviar su candidatura de manera directa al hotel, sin necesidad de tener que acudir a terceras páginas (portales de empleo, como Infojobs, Turijobs, etc.).

Sobre el acceso a otras páginas e información de interés relacionada, todos los hoteles ofrecían dicha posibilidad, siendo lo más común acceder desde la página del hotel a información de interés sobre la ciudad en cuestión, ya sean espectáculos, lugares para degustar la gastronomía típica, etc. Y finalmente sobre la indicación del software adicional necesario para poder visualizar el contenido de la web (Adobe Acrobat para documentos PDF, Flash, etc.), solo 3 hoteles indicaban qué software debía usar el usuario para abrir o descargar un archivo alojado en su web, siendo la mayoría de estos archivos folletos del hotel, entre otras informaciones. 


\subsubsection{Resultados para el apartado de contenido transaccional}

En cuanto al contenido transaccional, se muestra en la gráfica 8 , que ninguna las webs incluía herramientas de búsquedas directas, y por tal razón el usuario debía de navegar dentro de la página a paso de "clicks" para poder llegar de un lugar a otro dentro de la web. Además, ninguna de las webs soportaba la posibilidad de realizar los check-in online, y las que lo permitían, solo ofrecían dicha posibilidad a usuarios con un alto nivel de fidelización.

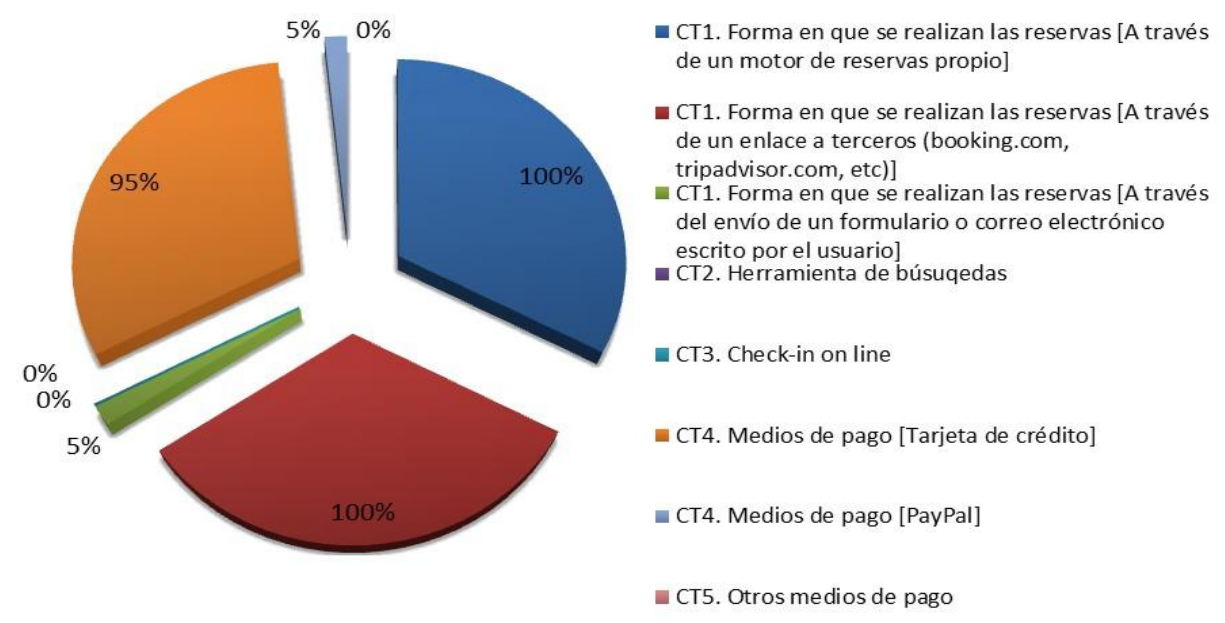

GRÁFICA 8 - CONTENIDO TRANSACCIONAL

FUENTE: Elaboración propia

En relación a las formas de pago, se puede observar que 19 (95\%) webs ofrecían la posibilidad de realizar el pago mediante tarjeta de crédito (Visa, American express, Master card, etc.), sin embargo, solo una daba la posibilidad de realizar el pago a través de Paypal (5\%), y ninguna brindaba la opción de hacer uso de otros mecanismos de pago online. Por otro lado, en los apartados "forma en que se realizan las reservas", se pudieron observar valores bastante altos en solo 2 de sus 3 ítems; y esto es porque todas las webs permitían que las reservas se realizaran por medio de un motor de reservas propio y así también, por medio de portales como lo son "Booking”, "Tripadvisor", etc., sin embargo, solo 1 web daba la posibilidad al usuario realizar las reservas por medio de otros medios, como lo serían los formularios destinados para ello o correo electrónico, como es el caso de la web del hotel NH collection Madrid (5\%). 
5.4.3 Resultados para el apartado de contenido comunicativo

Respecto al contenido comunicativo se analizaron "dos bloques de ítems", los cuales fueron por una parte a los canales de contacto, como son: la dirección, el teléfono de contacto, el e-mail, el boletín electrónico o Newsletter, la posibilidad de interactuar con la empresa de cara a la retroalimentación por medio de opiniones de clientes que se han alojado en el hotel en un momento previo, y la atención al cliente en caso de incidencias (GRÁFICA 9).

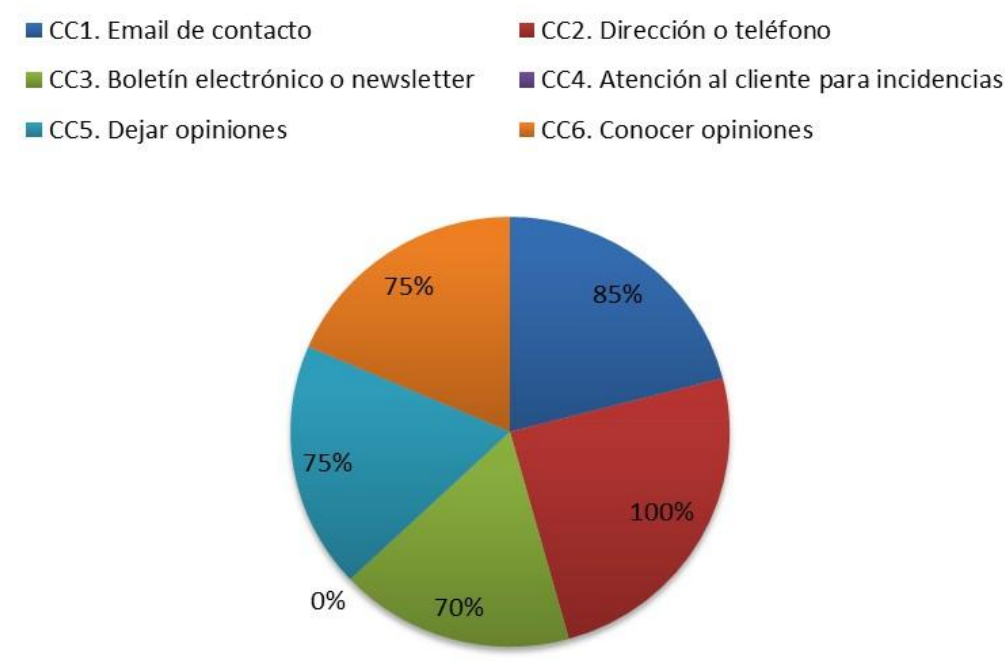

GRÁFICA 9 - CONTENIDO COMUNICATIVO.

FUENTE: Elaboración propia

Y por otra parte, se situó en el segundo bloque: la interacción social de la empresa por medio de las redes sociales, la cual debía estar concretamente identificada en la web para que de esta manera el usuario pudiera acceder directamente a ellas.

En el "primer bloque" como se ha denominado, se obtuvieron datos bastante positivos, lo cual da a conocer la buena comunicación que tenían las empresas por medio de sus webs. Se debe destacar que todas las webs incluían dirección y teléfono, lo cual es bastante importante, tanto para el cliente como para el posible cliente, de cara a poder contactar directamente en caso de cualquier cuestión que se estimara relevante, ya sea físicamente o por telefónicamente.

17 webs incluían e-mail de contacto (85\%), lo cual es bastante significativo en la sociedad de hoy en día; así, se puede destacar que este medio suele ser el más 
conveniente para usuarios que desearan ponerse en contacto con el hotel desde otros países, o simplemente para corroborar datos personales o en caso de cualquier otra incidencia en la que el usuario necesitase explicarse detalladamente por un medio escrito como lo es éste, etc.

15 webs incorporaron el apartado de opiniones (75\%), lo cual no hace más que añadir valor al hotel y a la misma web, ya que normalmente las opiniones sirven para mejorar, así como para orientar a los posibles clientes sobre como se suele desarrollar la prestación de los servicios ofrecidos en cada tipo de hotel.

14 webs ofrecieron la posibilidad de inscribirse en el newsletter del hotel (70\%), para así estar al día sobre las últimas novedades que éste pudiera ofrecer. Y por último, ninguno incluyó el apartado "atención al cliente para incidencias", como tal, sin embargo, pareció que dichas incidencias se solventaban y se dieron a conocer al hotel por medio del correo o el teléfono.

En cuanto al "segundo bloque", se encontró la presencia del hotel en las redes sociales, y la inclusión de los enlaces de dichas redes en la propia web.

En primer lugar se situó Facebook, red en la cual 18 hoteles tenían presencia y representaban dicho icono en la web (90\%). En segundo lugar, se localizó a Twitter con solo 2 webs por debajo de Facebook, concretamente con 16 webs de hoteles que lo incluyeron $(80 \%)$.

En tercer lugar se pudo observar que 13 hoteles contaron con presencia en Pinterest (65\%), 11 en Google+ (55\%), 8 en Instagram (40\%), 6 en Youtube (30\%); 3 tanto en Linkedin como en Flickr (15\%); y ninguno cuenta con presencia en Vimeo, por lo cual se determinó que hoy en día esa red social se encuentra en desuso o no es apreciada por los usuarios, y por dicha razón los hoteles prefirieron no incluirla. Todo esto es representado gráficamente en la gráfica 10. 


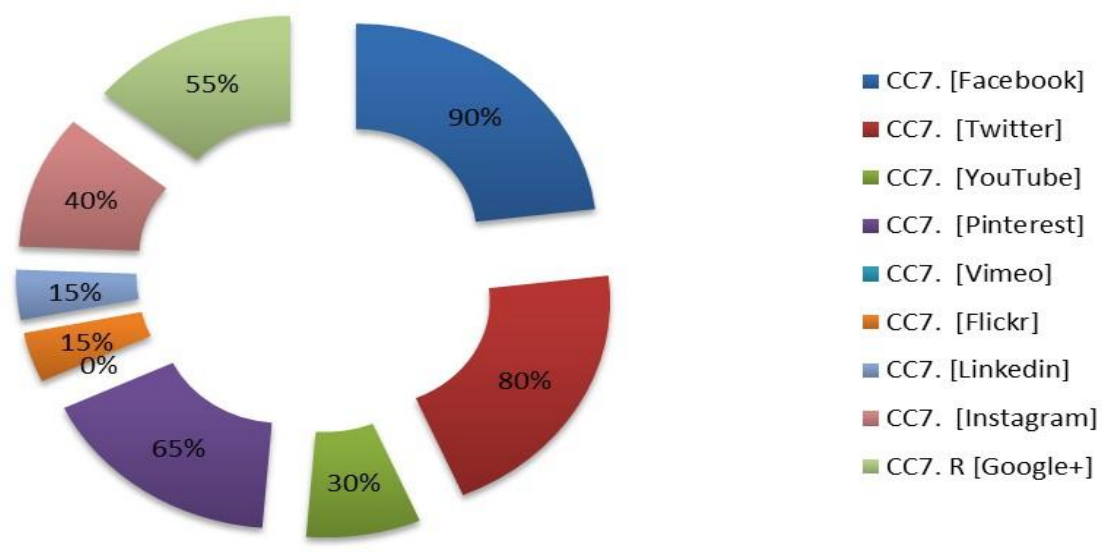

GRÁFICA 10 - REDES SOCIALES.

FUENTE: Elaboración propia

Tras todo lo expuesto anteriormente, en ambos "bloques", se puede determinar que la mayoría de las webs de los hoteles analizados poseían una alta efectividad en lo que al contenido referente a la comunicación se refiere.

\subsection{POSICIÓN DE LOS HOTELES SEGÚN LA PONDERACIÓN APORTADA POR IEW}

En cuanto a la posición de las webs de los hoteles analizados, si se ubicaran en un "ranking" a partir de los resultados obtenidos en el apartado "IEWB" de la plantilla del método utilizado, se destacaría que el hotel con mayor puntuación fue el Hesperia Resorts, siguiendo a éste el hotel Mandarin Oriental y el Urso Hotel and Spa.

Mientras que las webs de los hoteles las cuales obtuvieron las puntuaciones más bajas serían el hotel Miguel Ángel, el hotel Relais and Châteaux Orfila, hotel Villa Magna y el Westin Palace, sin embargo, las puntuaciones obtenidas por estos hoteles en cuanto a sus webs tampoco fueron tan bajas como tal, inclusive se podrían considerar como aceptables, pero al compararse con las demás web son consideradas como las más bajas. Todo esto es recogido tanto en el cuadro 2 como en la gráfica 11. 


\begin{tabular}{|l|r|}
\hline \multicolumn{1}{|c|}{ HOTEL } & IWEB \\
\hline Hesperia Resorts & 73,40 \\
\hline Mandarin Oriental & 72,36 \\
\hline URSO Hotel and Spa & 71,20 \\
\hline Wellington Madrid & 69,79 \\
\hline Adler & 69,25 \\
\hline AC Palacio del Retiro & 69,16 \\
\hline Melia Madrid & 68,75 \\
\hline Eurostars Madrid & 68,44 \\
\hline Silken Puerta & 68,26 \\
\hline NH Collection & 66,60 \\
\hline Hotel Villa Real & 66,44 \\
\hline InterContinental & 66,20 \\
\hline Barceló Emperatriz & 66,00 \\
\hline Hospes Puerta de & 65,74 \\
\hline Hotel Único Madrid & 64,42 \\
\hline Urban & 63,39 \\
\hline Hotel Miguel Angel & 61,80 \\
\hline Relais \& Châteaux & 59,34 \\
\hline Hotel villa Magna & 57,51 \\
\hline Westin Palace Hotel & 51,71 \\
\hline
\end{tabular}

CUADRO 2 - POSICIÓN DE CADA HOTEL SEGÚN IEWB

FUENTE: Elaboración propia

\section{IWEB}

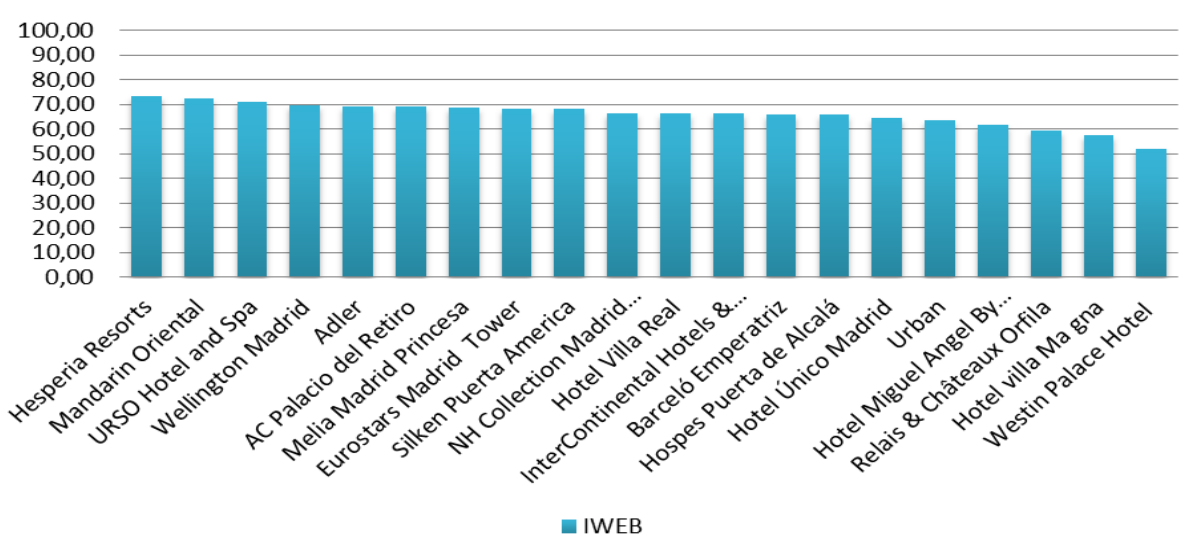

GRÁFICA 11 - RESULTADOS IEW

Todos los datos anteriormente expuestos, permitieron alcanzar las conclusiones que a continuación se presentan y que permiten concluir el presente trabajo, con un conjunto de recomendaciones, que son fruto de estos resultados. 


\section{CONCLUSIONES}

En primer lugar, es importante destacar que se han podido localizar los puntos fuertes de cada organización analizada, así como también las carencias de éstas, de manera individualizada.

Se pudieron apreciar factores, que de acuerdo con el método IEW, que los hoteles deberían potenciar en sus sitios web, como incluir el apartado de "ayuda en línea", ya que como se ha mencionado anteriormente en el análisis, solo 1 hotel de los 20 analizados incluyó dicha función; siendo esta característica bastante relevante para los usuarios, ya que tal opción brindó la posibilidad de recibir soporte ante cualquier duda o inconveniente de manera dinámica, ya sea mediante texto o por voz.

Como carencias más evidentes en las webs analizadas, es posible destacar que ninguna de las páginas estaba adaptada para personas con discapacidad, lo cual imposibilita a este tipo de usuario el uso efectivo de dichas webs.

Por otro lado, no todos los hoteles contaron con mapa web en sus páginas, a pesar de la gran importancia de esta característica, ya que ésta permite al usuario contar con una lista de páginas web estructuradas, con una arquitectura de enlaces adecuada para una efectiva y correcta navegación, y además permitiría a la web conseguir un mejor posicionamiento en motores de búsqueda.

También se debe indicar, que ninguna web ofreció la posibilidad de búsqueda por palabras clave o keywords, las cuales harían más sencilla la navegación del usuario dentro de la web, ya que éstas permitirían a los usuarios que por medio de criterios de búsqueda que se utilizan en Internet encontrar determinada información. Tampoco se suele incluir la historia de la empresa, pero las webs si suelen incluir un pequeño resumen corporativo, sin embargo, quizá la historia de la empresa sea más adecuada para aquellos posibles clientes los cuales deseen conocer el nacimiento y transcendencia del hotel a través de los años. Es notorio a su vez, como una posible carencia de las webs el no poder contar con un cuadro de búsqueda, el cual posibilitaría al usuario el acceder a la información que precisase de manera más sencilla y directa.

En cuanto a los principales puntos fuertes, es apreciable que todas las webs tenían un buen índice de velocidad, poseían presencia en los motores de búsquedas, siendo sus puestos normalmente el primero; por otra parte, la mayoría de las webs resultaron dinámicas, contaban con un lenguaje muy sencillo; ofrecían la posibilidad 
utilizar la página en diversos idiomas, lo cual es un punto importante para este tipo de web, donde los usuarios son tan diversos, y no necesariamente hablan español o inglés, por este motivo la mayoría de las webs analizadas incluyeron además de estos dos idiomas, otros, los cuales van desde los más tradicionales, como lo serían el francés, el alemán, el italiano o el portugués, así como otros menos habituales como el coreano, el ruso o el holandés, lo cual permitió al hotel la posibilidad de que usuarios que solo hablen sus lenguas natales puedan tener un eficaz manejo de la web.

Para finalizar, las páginas web analizadas han obtenido puntuaciones bastante positivas, sin embargo, aún cuentan con aspectos mejorables de cara a alcanzar una mejor calidad web, y así brindar al usuario una mejor experiencia dentro de la misma, y por consiguiente ganar un mejor posicionamiento para sus webs, lo cual sería igual a mayores ingresos.

\section{REFERENCIAS}

ACERA, M. A. Analítica Web. Editorial Anaya Multimedia. 304 p., 2012. ISBN10: 8441531471, ISBN-13: 978-8441531475.

BAÑOS GONZÁLEZ, M. Análisis de la competencia en las páginas web de las Universidades. Icono 14, v. 2, n. 1, 2004.

BECK, S. Evaluation Criteria: The Good, The Bad and the Ugly; or, why it is a Good Idea to Evaluate Web Sources, 2005. Disponible en: <http://lib.nmsu.edu/instruction_backup/evalcrit.html $>$. Accedido el: 1 de Octubre de 2016.

BENBUNAN-FICH, R. "Using protocol analysis to evaluate the usability of a commercial Web site." Information \& Management (39), p. 151-163, 2001.

BORGES, J. A.; MORALES, I.; RODRIGUEZ, N. J. Page design guidelines developed through usability testing. Human factors and Web development, 137-152, 1998.

BUCKLAND, M. La qualitat de la informació al web". BiD: textos universitaris de biblioteconomia i documentació, n. 31, desembre, 2013. Disponible en: <http://bid.ub.edu/31/buckland1.htm>. Accedido el: 04/05/2016. DOI: http://dx.doi.org/10.1344/BiD2014.31.1

BUENADICHA MATEOS, M.; CHAMORRO MERA, A.; MIRANDA GONZÁLEZ, F. J.; RODRIGO GONZÁLEZ LÓPEZ, Ó. A new Web assessment index: Spanish universities analysis. Internet research, 11 (3), p. 226-234, 2001. 
BUHALIS, D.; LAW, R. Progress in information technology and tourism management: 20 years on and 10 years after the Internet-The state of eTourism research. Tourism Management, v. 29, issue 4, aug. 2008, p. 609-623, 2008.

CASTAÑEDA, L.; GUTIÉRREZ, I. Redes sociales y otros tejidos online para conectar personas. Aprendizaje con redes sociales. Tejidos educativos para los nuevos entornos, p. 17-39, 2010.

CASTELLÓ MARTÍNEZ, A. CRM Social: La orientación empresarial hacia el cliente en plataformas 2.0. REDMARKA - CIECID - Unidad de Investigación en Marketing Aplicado-Universidad de A Coruña Año IV, número 7, v. 3, p. 3-36, 2011.

CASTELLÓ MARTÍNEZ, A. Estrategias empresariales en la Web 2.0. Las redes sociales online, ECU, Alicante. p. 49- 143, 2010.

CONESA FUENTES, M. C.; PAÑOS ÁlvAREZ, A. Evaluando la calidad de páginas web de enfermería al primer clic, Estudio de casos. Tempus Vitalis, v. 6, n. 2, p. 1-13, 2006.

CORRÊA, C. H. W. Análise das estratégias de marketing adotadas pela EMBRATUR no portal Braziltour.com. Turismo e Sociedade, v. 5, n. 1, 2012.

DE OLIVEIRA-ARRUDA, D.; GONDIM-NOGUEIRA, C.; DUTRA-DIAS, G. A Importância Relativa dos Fatores de Qualidade e seus Determinantes na Seleção de Cursos de Línguas Estrangeiras em Redes Sociais. Revista Electrónica Educare, v. 1, 19 (3), p. 1-23, 2015.

DE LA TORRE BARBERO, M. J.; ESTEPA LUNA, M. J.; LÓPEZ-PARDO MARTÍNEZ, M.; LEÓN MÁRQUEZ, M.; SÁNCHEZ LAGUNA, F.; TOLEDANO REDONDO, S. Evaluación de la calidad de las páginas webs de los hospitales del Sistema Sanitario Público de Andalucía. Revista de Calidad Asistencial, p. 127-134, 2014. DOI: $10.1016 /$ j.cali.2013.11.006

DEL RÍO, M. D. L. C.; GARCÍA, J. Á.; GÂNDARA, J. M. G.; VALDUGA, V.; GONZÁLEZ, P. R. Ruta del Vino Ribeira Sacra (Galicia-España): Análisis desde el punto de vista de la oferta enoturística. Turismo e Sociedade, v. 7, n. 3, 2014.

DÍAZ-LUQUE, P.; JIMÉNEZ MARÍN, G. La web como herramienta de comunicación y distribución de destinos turísticos. Análisis y modelos. Cuestiones publicitarias, (1) 18, p. 39- 55, 2013.

FERNÁNDEZ-CAVÍA, J.; VINYALS MIRABENT, S.; LÓPEZ PÉREZ, M. Qualitat dels llocs web turístics oficials de les comunitats autònomes espanyoles. BiD: textos universitaris de biblioteconomia i documentació, n. 31, Des., 2013. Disponible en: <http://bid.ub.edu/31/fernandez1.htm>.

DOI: http://dx.doi.org/10.1344/BiD2014.31.6. Accedido el: 01/05/2016. 
FERNÁNDEZ-CAVIA, J.; CASTRO, D. Comunicación y branding en los sitios web nacionales de turismo. Cuadernos. info, (37), 167-185, 2015.

FOLGADO-FERNÁNDEZ, J. A.; PALOS-SÁNCHEZ, P. R.; CAMPÓN-CERRO, A. M.; HERNÁNDEZ-MOGOLLÓN, J. M. Gastronomic products with identity and the development of the tourism destination. A study on cheese routes in Spain. International Journal of Scientific Management and Tourism, 3 (1), p. 93-109, 2017.

GONZÁLEZ-SOLTERO, R.; BLANCO, M.J.; BISCAIA, J. M.; MOHEDANO, R.B.; GRILLE-MARISCAL, M.; BLANCO, M. A. Análisis del contenido, posicionamiento y calidad de páginas web en español relacionadas con la nutrición y los trastornos de la conducta alimentaria. Nutrición Hospitalaria, 31 (n. 3), p. 1394-1402. 2014.

GONZÁlEZ LÓPEZ, O. R.; BAÑEGIL PALACIOS, T. M.; BUENADICHA MATEOS, M. El índice cuantitativo de calidad web como instrumento objetivo de medición de la calidad de sitios web corporativos. Investigaciones Europeas de Dirección y Economía de la Empresa, v. 19, n. 1, 2013, p. 16-30 Academia Europea de Dirección y Economía de la Empresa Vigo, España, 2013.

GRÁVALOS MACHO, D. La calidad de una página web como herramienta de comunicación, v. 19, p. 1-19, Universidad Europea de Madrid, 2013.

HEITMANN, M.; LEHMANN, D. R.; HERRMANN, A. Choice goal attainment and decision and consumption satisfaction. Journal of Marketing Research, 44, p. 234$250,2007$.

HOFFMAN, D. L.; NOVAK, T. P. X. Marketing in hypermedia computer mediated environments: conceptual foundations. Journal of Marketing, v. 60, p. 50-68, 1996.

ISLAM, M. N.; BOUWMAN, H. Towards user-intuitive web interface sign design and evaluation: A semiotic framework. International Journal of Human-Computer Studies, 86, p. 121-137, 2016. Doi:10.1016/j.ijhcs.2015.10.003

ISO. International Organization for Standardization, ISO/ IEC 14598-4, Information Tecnology- Software Product Evaluation- Part 3: Process For Developers, Software Engineering: Draft, 1998a.

ISO. International Organization for Standardization, ISO/IEC FDC 9126 - 1,2. Information Technology- Software Product Quality, Part 1: Quality Model: Draft, 1998b.

ISO. International Organization for Standardization, ISO/IEC 9241. ISO 9241 154:2013 Preview Ergonomics of human-system interaction -- Part 154: Interactive voice response (IVR) applications, 2013. 
KANERVA, A.; KEEKER, K.; RISDEN, K.; SCHUH, E.; CZERWINSKI, M. Web usability research at Microsoft Corporation. Human Factors for World Wide Web Development, Lawrence Erlbaum, New York, United States of America, 1997.

KOTLER, P. Administração de Marketing. 5. ed. São Paulo: Editora Atlas, 1998.

MILLS, J.; LAW, R. Handbook of consumer behaviour, tourism and the internet. Psychology Press. New York, 2004.

MIRANDA GONZÁLEZ, F. J.; BAÑEGIL PALACIOS, T. M. Quantitative evaluation of comercial web sites: an empirical study of Spanish firms, elservier.com, International Journal 314 of Information Management 24, Abr. 2004, p. 313-328, 2004.

MIRANDA GONZÁLEZ, F. J.; BARRIUSO IGLESIAS, M. C.; CORTÉS GÓMEZ, R.M. La banca por Internet en España, aplicación del índice de evaluación web, Boletín Económico de ICE, n. 2855, p. 15-30, 2005.

MIRANDA, F. J.; CHAMORRO, A.; VALERO, V.; MAESTRE, J. Quantitative Assessment of Football Web Sites: An Empirical Study of the Best European Football Club. Journal of Service Science and Management, v. 3, n. 1, 2010, p. 110116. DOI: $10.4236 /$ jssm.2010.31014.

MIRANDA, F. J .; RUBIO, S.; CHAMORRO, A. An assessment Methodology for Hotel Websites: Application to the Top 10 Cities Destinations in the World. Information Resources Management Association (USA), 2015. DOI: 10.4018/978-14666-6543-9.ch018.

MOUSTAKIS, V.; TSIRONIS, L.; LITOS, C. A model of web site quality assessment. The Quality Management Journal, 13 (2), 22, 2006.

MURRAY, P. F. Thylacinus megiriani, a new species of thylacine (Marsupialia: Thylacinidae) from the Ongeva local fauna of central Australia. Records of the South Australian Museum, 30, p. 43-61, 1997.

NIELSEN, J. Top ten Web design mistakes of 2003. Disponible en: $<$ http://useit.com/alertbox.>. Acceso el: 2 de Septiembre de 2016.

O'REILLY, T. What is Web 2.0: Design patterns and business models for the next generation of software, 2007, Communications \& Strategies, 1, p. 17-37.

O'REILLY, T. Web 2.0: Compact definition?. (1 October), at http://radar.oreilly.com/2005/10/web-20-compact-definition.html, accesible el 31 Octubre 2016.

PARK, S.; WANG, D.; FESENMAIER, D. Assessing structure in american online purchase of travel products. Anatolia: An International Journal of Tourism and Hospitality Research, 22 (3): p. 401-417, 2011. 
PEI Y.; JIAO G. The research of web usability design. Computer and automation engineering (iccae), 2nd international conference on (v. 4, p. 480-483). IEEE, 2010.

RASTROLLO, M. A.; ALARCÓN, P. El turista ante el comercio electrónico, Revista de Estudios Turísticos, 142: p. 97-116, 1999.

RODRÍGUEZ-MARTÍNEZ, R.; CODINA, L.; PEDRAZA-JIMÉNEZ, R. Indicadores para la evaluación de la calidad en cibermedios: análisis de la interacción y de la adopción de la Web 2.0. Revista Española de Documentación Científica, 35 (1): p. 61-93, 2012. DOI: 10.3989/redc.2012.1.858.

RODRIGUEZ RANGEL, C.; SANCHEZ RIVERO, M. Análisis de las Páginas Webs de los Espacios Naturales como destinos turísticos a través del Modelo de Rasch: Una Aplicación Al Caso De Rusia. Revista de Análisis Turístico, (18), p. 33-43, 2014.

RUBIO LACOBA, S.; MIRANDA GONZÁLEZ, F. J.; CHAMORRO MERA, A. La presencia en internet de los principales operadores logísticos en España, XVI CONGRESO NACIONAL DE ACEDE. Septiembre 2006, Valencia, 2006.

SANGWON, L.; KOUBEK, R. J. The effects of usability and web design attributes on user preference for e-commerce web sites. Computers in Industry, v. 61, issue 4, p. 329-341, 2010.

SCHMIDT, S. Evaluación de los Sitios Web de los Hoteles e Implicaciones para la Gestión del Marketing Hotelero, en Jurado, A.S y CP (Dir.). Servicio de publicaciones de la Universidad de Islas Baleares, 2006.

VORA, P. Human Factors methodology for designing web sites. In: Human Factors and web Development, ed. E. Grose, C. Forsythe, and J. Rather. N. N. J.: Lawrence Erlbaum Associates, 1998.

WERTHNER, S.; KLEIN S. Information technology and tourism-A challenging relationship. International Journal Tourism Researchs, 2, p. 447-448, 1999.

WOODSIDE, A. G.; DION, C. P. Usefulness of Government and Private Destination Websites, in Advances in Culture, Tourism and Hospitality Research, 4, p. 69-137, 2010 .

XIANG, Z.; WÖBER, K.; FESENMAIER, D. R. Representation of the online tourism domain in search engines. Journal of Travel Research, 47 (2), p. 137-150, 2008.

ZHU, X.; GAUCH, S. Incorporating quality metrics in centralized/distributed information retrieval on the World Wide Web. In Proceedings of the 23rd annual international ACM SIGIR conference on Research and development in information retrieval (pp. 288-295). ACM, 2000.

Recebido em: 13-01-2017.

Aprovado em: 12-02-2017. 